\title{
Experimental study on the rheological behaviour of coal ash slurries
}

\author{
K.M. Assefa, D.R. Kaushal* \\ Department of Civil Engineering, Indian Institute of Technology Delhi, Hauz Khas, New Delhi - 110016, India. \\ ${ }^{*}$ Corresponding author. Tel.: +91-9818280867. Fax:+91-11-26581117. E-mail: kaushal@civil.iitd.ac.in
}

\begin{abstract}
Extensive experimental investigations were carried out to evaluate the rheological behaviour of fly ash (FA) slurry without and with the addition of bottom ash (BA) and BA slurry without and with the addition of FA. The FA slurries exhibited Bingham behaviour at solid mass concentrations ranging from $60-65 \%$ and mixing proportions from 10 $40 \%$. A substantial reduction in yield stress was observed except for mixing proportion of $40 \%$ on which the yield stress and viscosity were increased drastically for all solid concentrations. Hence, it can be concluded that the yield stress and viscosity of FA slurry were very much influenced by adding BA up to the mixing proportion of $30 \%$. The rheological behaviour of BA slurries with and without the addition of FA in proportions of 10-50\% was investigated and exhibited Newtonian behaviours for solid mass concentrations ranging from $30-50 \%$ without and with the addition of FA. The viscosity increases with increasing the solid concentrations and proportion of FA. Based on these experimental data, a correlation was developed to predict the relative viscosity of BA slurries as a function of solid volume fraction and FA mass proportion of $0-50 \%$ and the RMSE and $\mathrm{R}^{2}$ values showed good agreement between the experimental and the predicted data.
\end{abstract}

Keywords: Coal ash slurry; Newtonian fluid; Yield stress; Plastic viscosity; Relative viscosity.

\section{INTRODUCTION}

Large quantities of fly ash (FA) and bottom ash (BA), usually in the ratio of $4: 1$, are produced from the combustion of coal for electric power generation. These ashes are commonly transported in slurry form from the power plant to ash ponds through pipelines at the solid mass concentration ranging from 10 to $15 \%$ that makes the ash disposal operational system uneconomical due to large water requirement and pumping energy wastage. Hence, it would be wiser to use highly concentrated slurry. Recently high concentration slurry disposal system is emerging as the preferred option to transport coal ash as it is economical and environmentally friendly (Chandel et al., 2010; Seshadri et al., 2005). But this will increase the values of slurry viscosity and shear stress, which in turn increase the pumping power. Low values of viscosity and shear stress demands less pumping power. These flow properties are generally expressed by slurry rheological characteristics. Thus, it is important to know the rheological behaviour at various solid concentrations for the design of a pipeline system.

The rheological characteristics of ash slurry depend on several parameters such as particle shape, particle size distribution, solid concentration, viscosity and so on. According to Biswas et al. (2000) investigation the physical and rheological properties of FA and BA samples collected from various thermal power plants across the regions in India showed large variations. Hence it is difficult to correlate on one sample properties to the others and hence needs individual investigations. This entails the necessities of conducting a bench scale test on rheological properties of ashes at higher solid concentrations.

Study indicates that additives of different nature help reduce the values of viscosity and shear stresses of slurry, thus improving flow behaviour and creating a good chance to increase the percentage of solid parts in slurry (Vlasak et al., 2010). In literature, reports have been made on the effects of various additives on rheological properties of the FA slurry at high concentrations (Chandel et al., 2009a; Mosa et al., 2008). Investigations also carried out for $\mathrm{BA}$ as additives on the FA slurry at mixing ratio of 4:1 (Chandel et al., 2010). But not much work has been reported on the effects of adding BA in the
FA slurry and adding FA in the BA slurry on other possible mixing ratios.

Hence, in the present study, an attempt has been made to evaluate the rheological behaviour of BA slurry at $30,40 \%$ and $50 \%$ mass concentration and FA slurry at 60,62 , and $65 \%$ mass concentration. Solid FA was used as additive in the BA slurry and solid BA was used as additive for the FA slurry. For all slurry concentrations addition proportions of $0,10,20,30,40$ and $50 \%$ were chosen. Based on the rheological data, suitable discussions and conclusions have been made for its effective transportation through hydraulic pipelines.

\section{LITERATURE REVIEW}

A number of techniques which are capable of reducing frictional pressure drop either by altering the rheological properties or by reducing the impact of adverse flow properties of the slurries, have been investigated in the past decades. The literature review reveals that the addition of drag reducing agents will change the rheological parameter of ash slurry. Kolar et al. (1988) carried out field experiments in $18 \mathrm{~km}$ long, $600 \mathrm{~mm}$ diameter pipeline to investigate the effect of drag reducing polymer (Separan AP-302) on a pulverized ash and slag slurry and they observed $22 \%$ increasing of concentration and pipeline load capacity due to drag reduction effect. Seshadri et al. (2005) investigated pipeline transportation of the FA slurry with Sodium hexa-metaphosphate added at $0.1 \%$ concentration by mass and they found that there is a significant reduction in the viscosity of the slurry. Verma et al. (2006) studied the rheological behaviour of FA slurry without and with the addition of Sodium hexa-metaphosphate at $0.1 \%$ concentration by mass for different particle size distributions and concentrations and they found that particle size distribution and concentration of solids affected more to the slurry rheology in non-Newtonian comparison to the Newtonian nature of slurry. Mosa et al. (2008) assessed the effect of three types of additives, namely-sulphuric acid, sodium tripolyphosphate and sodium carbonate at mass concentrations from 0.5 to $1.5 \%$ on the rheological characteristics of coal-water slurry. They found that apparent viscosity and flow properties decreases with an increase in additives. 
According to Chandel et al. (2009a) investigation, adding $0.2 \%$ by mass of sodium carbonate and Henko detergent $(5: 1)$ could drastically reduce the yield stress and Bingham plastic viscosity of $\mathrm{FA}$ at concentration ranging from 50 to $70 \%$ by mass. Naik et al. (2009a, 2009b, 2011) studied the effects of addition of Cetyl Trimethyl Ammonium Bromide and Sodium Salicylate on the rheological Properties of FA-water suspensions for $20 \%$ to $40 \%$ concentration at temperature ranging from 20 to $40^{\circ} \mathrm{C}$ and found that the viscosity and shear stress decreased for all the cases with increase in temperature and the slurry without additive showed shear thickening behaviour but exhibited almost Newtonian pattern with a zero yield stress when the concentration of the additive solution increased gradually with an incremental value of $0.1 \%$ by mass. According to their investigation the effective additive concentration range was found to be from $0.2 \%$ to $0.3 \%$ by mass. Kunal and Kundan (2012) experimentally evaluated the effects of three types of additives (cationic, anionic and non-ionic polymer) on the rheological behaviour of FA slurry at $40 \%$ slurry mass concentration and found that all the additives reduce the viscosity and shear stress of the FA slurry.

Senapati and Mishra (2012) investigated the rheological properties of FA and FA-BA slurries at high solid concentrations and the results indicated that the addition of BA fractions to FA slurry at a given solids concentration decreased head loss value which in turn reduces the pumping power requirement. Umesh et al. (2003) experimentally studied the effect of particle gradation on the pressure drop and concentration profiles of ashes and observed that slurry with a mix of fine and coarse particles requires less energy for transportation and at some optimum particle size distribution, the energy required is even less than that required for the fine slurry. According to their report the optimum particle size distribution for transport of FA-BA mix is the one which corresponds to a solid phase having FA-BA ratio in the range $4: 1$ to $3: 2$. Senapati et al. (2013) experimentally analysed the friction mechanism and suspension of BA conveyed in FA slurry in solid concentration range of $62.5 \%-67.5 \%$ by weight using rheological and experimental data and concluded that the addition of BA to FA slurry reduced the apparent viscosity of the mixture slurry and also confirmed that the disposal of mixture slurry at a high solid concentration could be beneficial as the addition of BA provided lesser resistance affecting the head loss. According to experimental investigation of Senapati et al. (2010), the rheological behaviours of various FA slurries were highly pseudo-plastic which can be described by a nonNewtonian power law model at higher solid volume fractions in the range of 0.32 to 0.49 . They also concluded that the relative viscosity is very much sensitive to the concentration of solids, particle size and particle size distribution.

Vlasak and Chara (2009) experimentally investigated the effect of slurry composition and volumetric concentration on the flow behaviour of fluidic FA and BA slurries and sand slurries and reported that the addition of BA induces significant changes on the flow behaviour of fluidic FA slurries. Vlasak and Chara (2011) experimentally investigated the flow behaviour and pressure drop of dense slurries with different particle diameter at slurry concentration ranging from $6 \%$ to $51 \%$ in pipeline loops with inner diameters of 17.5 and $26.8 \mathrm{~mm}$ and concluded that the addition of coarse-grained material can possibly reduce the flow resistance of the concentrated finegrained material. The same authors also observed that the hydraulic gradient decreases markedly, the laminar-turbulent transition is reached at lower flow velocities, and a higher ash slurry concentration can be reached (Vlasak and Chara, 2004).
According to Panda and Pradhan (2014) the FA slurry shows Bingham behaviour at $60 \%$ solid concentration and above, while the addition of BA changes its behaviour from Bingham to Pseudo-plastic and also observed that addition of BA at the ratio $3: 2$ lowers the viscosity to a minimum.

\section{EXPERIMETAL SETUP AND MEASUREMENTS}

Standard bench scale test was carried out to determine the physical and rheological properties of the slurry. These extensive experiments were done in the Water Resources Simulation Laboratory of Civil Engineering Department, IIT Delhi. The rheological analysis was conducted by using an advanced computerized rotational rheometer, RheolabQC manufactured by Anton Paar Company Ltd., Germany. The rheometer consists of a high-precision encoder and a highly dynamic EC motor. It can be operated either via the robust keypad or via an external keyboard connected to the interface. The data can be read out immediately, stored for reading out later, or sent to a connected printer by a software program called RheoPlus. The rheometer consists of measuring cup CC27 and a sensor system ST22 - 4V - 40 having four bladed Vane rotors, with $40 \mathrm{~mm}$ length and $22 \mathrm{~mm}$ diameter.

For the tests, around $75 \mathrm{~g}$ of the slurry was prepared by mixing the required quantity of solid materials with tap water to obtain the desired mass concentration $\left(\mathrm{C}_{\mathrm{m}}\right)$. An electronic balance with a deviation of $\pm 10^{-4} \mathrm{~g}$ was used for weighing the solid materials accurately.

Shear rate under the controlled rate ranging from $20 \mathrm{~s}^{-1}$ to $200 \mathrm{~s}^{-1}$ at 10 measuring intervals was applied for about 2 minutes to measure the corresponding shear stress and viscosity. All the measurements were repeated several times to minimize errors occur during tests. Further, at each concentration, measurements were done at least two samples of the same material to assess the extent of repeatability. The repeated sets of sample data on shear stress and viscosity at any given shear rate agreed within $\pm 3 \%$.

\section{Test materials}

The materials used in this specific study were FA and BA. Since the slurry is to be transported through an ordinary water medium in the pipelines, so ordinary tap water was chosen for the preparation of slurry sample. Given that the BA samples obtained contain a small percentage of fines the samples were first sieved to separate the fines portion from the coarser in the samples prior to testing and for BA as additives only particles retained on the BS 200 sieve were used. To investigate the rheological behaviour of the BA slurries, sample preparation was done based on the procedures adopted by Gahlot et al. (1988) in which samples having different size distributions and top particle sizes were prepared by scalping the large sized particles from the original sample. This criterion would help in the prediction of the rheology of BA slurry based on the experimental measurements.

\section{Range of parameters}

The experiments were carried out for slurries of FA, BA and mixtures of FA and BA at mixing ratios of 9:1, 4:1, 7:3, 3:2, and $1: 1$. The solid mass concentrations of 60,62 , and $65 \%$ were chosen for FA slurry without and with the addition of BA and 30,40 and $50 \%$ were selected for BA slurry without and with the addition of FA. The shear rates during the measurements were varied from $20 \mathrm{~s}^{-1}$ to $200 \mathrm{~s}^{-1}$ with a step of $20 \mathrm{~s}^{-1}$ each. 
These ranges correspond to the magnitudes of shear rates usualusually recommended in the literature for slurry flow.

\section{RESULTS AND DISCUSSIONS \\ Physical properties of solid materials}

The representative samples of FA and BA were obtained from the Ahmedabad thermal power plant in Gujarat state, India. The physical properties of the samples have been determined and shown in Table 1, Table 2 and Figure 1. The specific gravity was measured by the standard Pycnometer method. The average specific gravity of FA and BA are 2.1 and 2.25 , respectively. The settling behaviour of solid sample in suspension is determined by preparing $30 \%$ mass concentration, mix thoroughly and allowing it to settle in a graduated measuring jar till the level of the settled solids become constant and is called static settled concentration. In a meantime, the level of the slurry was recorded at regular intervals of time during the process of settling to determine the settling rate of the slurry. The maximum static settled concentrations of the sample slurry are $51.2 \%$ and $72.1 \%$ for BA and FA respectively as shown in Table 1 . The measured $\mathrm{pH}$ values of BA \& FA ranges from 7.52 to 7.24 up to $70 \%$ mass concentrations (Table 2 ). The particle size distribution (PSD) was obtained by two methods namely, sieve analysis and hydrometer analysis. At first the sample is washed with water over a BS 200 mesh and then dried in oven. Sieve analysis has been done for particle size larger than $75 \mu \mathrm{m}$ and the percentage of the solids retained was calculated following the standard procedures. Standard hydrometer technique was used for the finer particles $(<75$ $\mu \mathrm{m})$. The PSD for all samples in semi-log form was presented in Figure 1. The maximum particle size of FA and BA were 300 $\mu \mathrm{m}$ and $355 \mu \mathrm{m}$ respectively. $95 \%$ of the particle sizes are below $75 \mu \mathrm{m}$ for FA and $85 \%$ of the particle sizes are above 75 $\mu \mathrm{m}$ for BA. The median particle diameter, $\mathrm{d}_{50}$, of FA and BA are $8 \mu \mathrm{m} \& 92 \mu \mathrm{m}$, respectively.

Table 1. Settling characteristics of BA and FA slurries.

\begin{tabular}{lllllllllllll}
\hline Time $(\min )$ & 0 & 0.25 & 0.5 & 1 & 2 & 10 & 30 & 60 & 180 & 480 & 720 & 1440 \\
$\mathrm{C}_{\mathrm{m}}(\%)-\mathrm{BA}$ & 30 & 34.43 & 41.18 & 50 & 50.6 & 50.6 & 50.6 & 50.6 & 50.6 & 51.2 & 51.2 & 51.2 \\
$\mathrm{C}_{\mathrm{m}}(\%)-\mathrm{FA}$ & 30 & 30.3 & 31.5 & 32.8 & 34.1 & 45.5 & 58.5 & 60.1 & 61.8 & 70.1 & 72.1 & 72.1 \\
\hline
\end{tabular}

The static settled concentration of BA at $30 \%$ initial concentration is $\mathrm{C}_{\mathrm{m}}=51.2 \%\left(\mathrm{C}_{\mathrm{v}}=31.8 \%\right)$.

The static settled concentration of FA at $30 \%$ initial concentration is $\mathrm{C}_{\mathrm{m}}=72.1 \%\left(\mathrm{C}_{\mathrm{v}}=55.2 \%\right)$.

Table 2. $\mathrm{pH}$ values for BA and FA slurries at various mass concentrations.

\begin{tabular}{llllllll}
\hline $\mathrm{C}_{\mathrm{m}}(\%)$ & 0 & 20 & 30 & 40 & 50 & & \\
$\mathrm{pH}$ value of BA & 7.61 & 7.52 & 7.48 & 7.46 & 7.45 & & \\
$\mathrm{C}_{\mathrm{m}}(\%)$ & 0 & 20 & 30 & 40 & 50 & 60 & 70 \\
$\mathrm{pH}$ value of FA & 7.61 & 7.41 & 7.36 & 7.33 & 7.29 & 7.25 & 7.24 \\
\hline
\end{tabular}

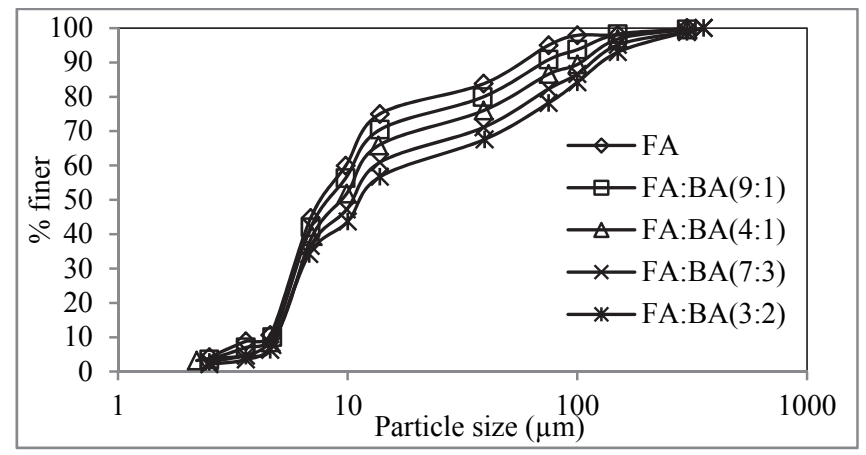

(a) FA with different FA:BA proportions

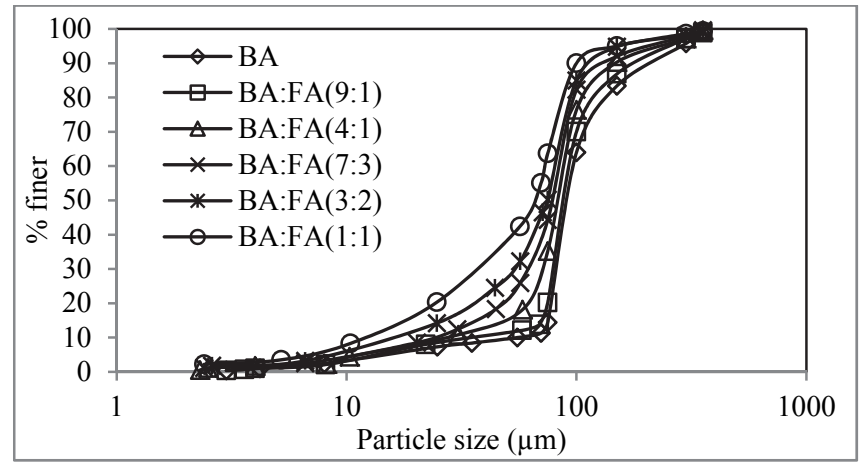

(b) BA with different BA:FA proportions

Fig. 1. Particle size distributions of ash samples. 

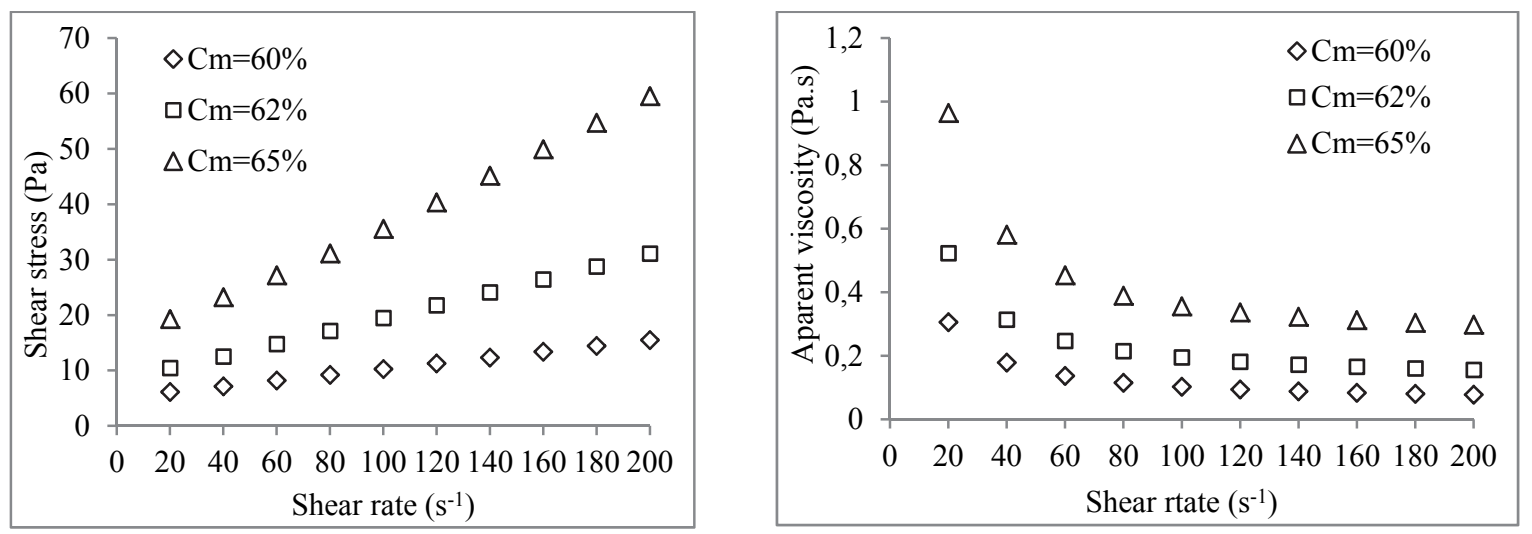

(a) Rheogram of FA slurry at different solid mass concentrations
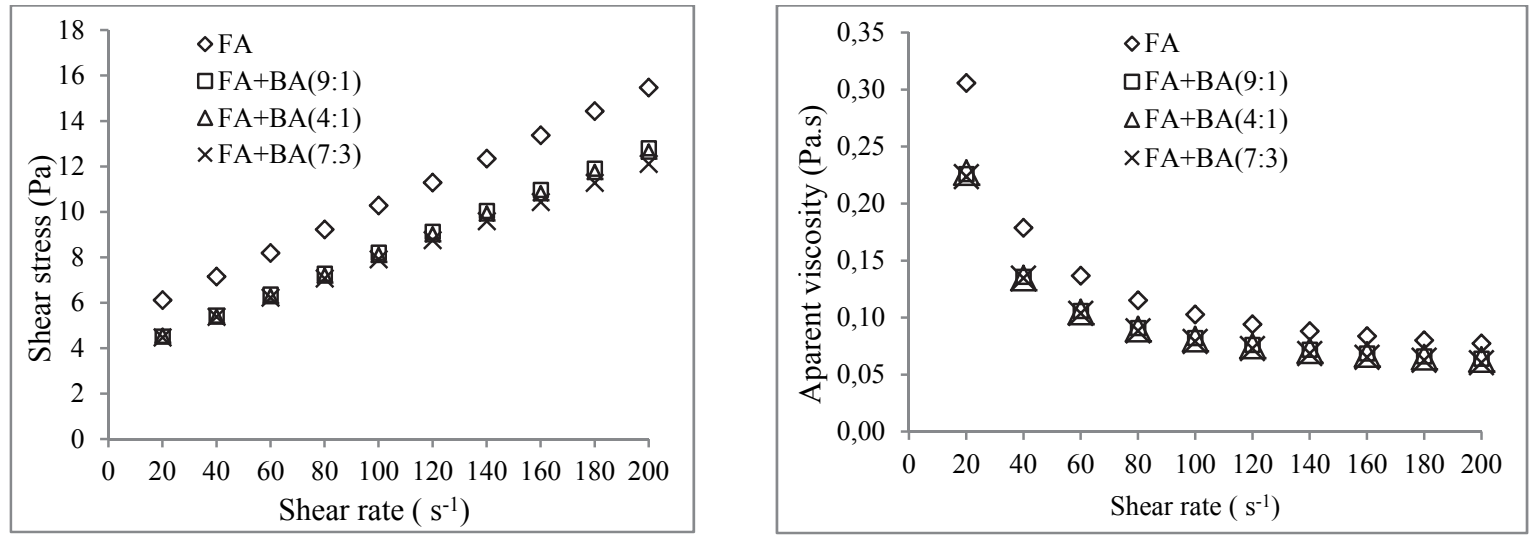

(b) Rheogram of FA \& mixture of FA and BA slurries at $\mathrm{Cm}=60 \%$
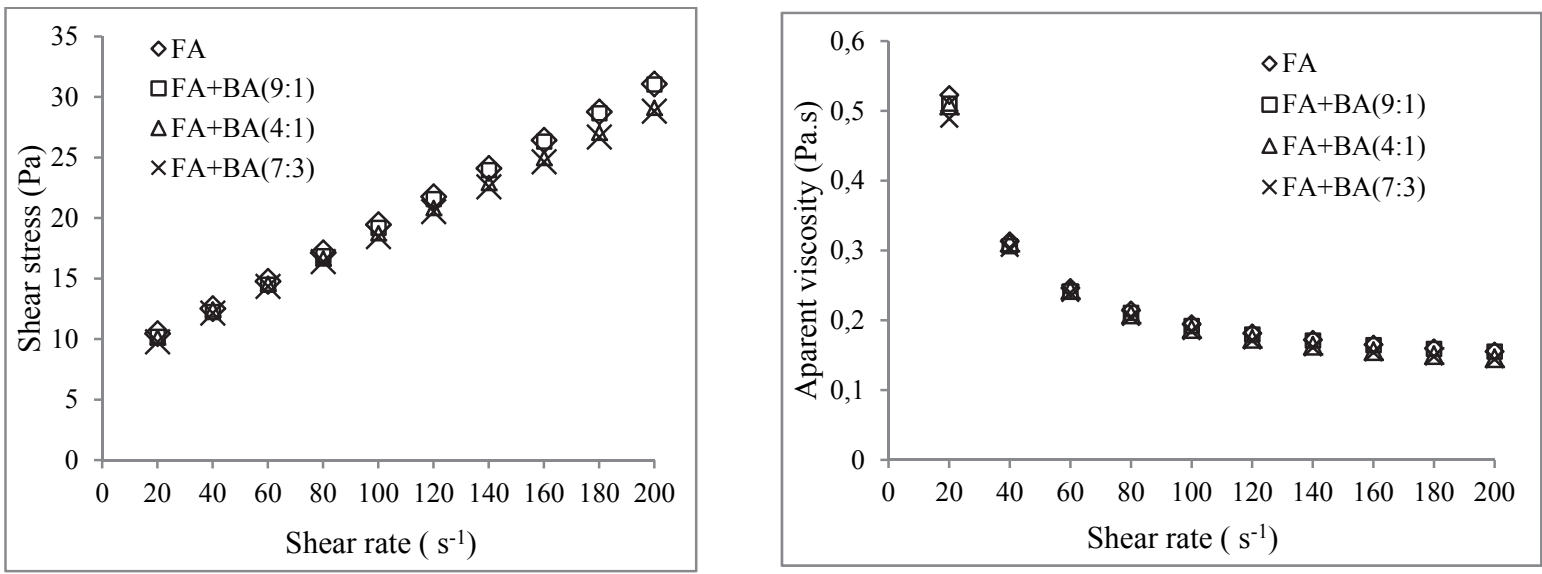

(c) Rheogram of FA \& mixture of FA and BA slurries at $\mathrm{Cm}=62 \%$
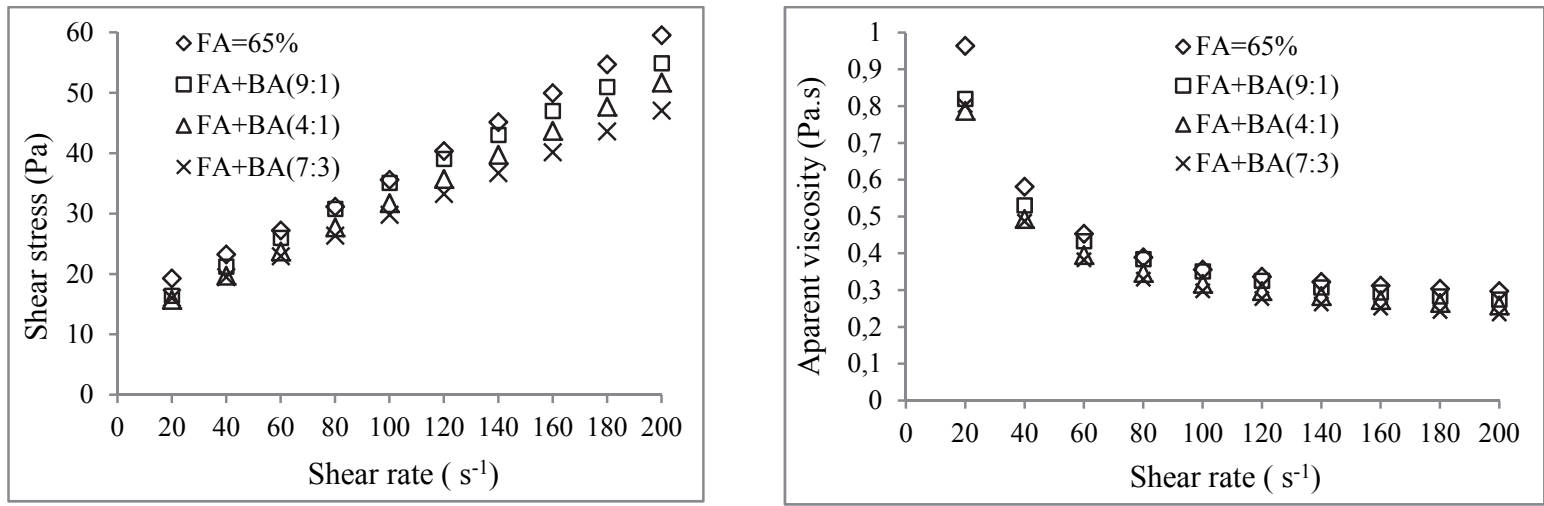

(d) Rheogram of FA \& mixture of FA and BA slurries at $\mathrm{Cm}=65 \%$

Fig. 2 (a-d). Rheogram of FA slurry without and with the addition of BA. 


\section{RHEOLOGICAL PROPERTIES OF THE SLURRY Effect of the addition of BA on the FA slurry}

Figure 2 (a-d) showed the rheological properties of FA without and with the addition of BA at solid mass concentration of $60 \%, 62 \%$ and $65 \%$. The data showed that the variation of shear stress with shear rate at all concentration follow a straightline behaviour. It has also observed that the values of the yield stress are non-zero for all sets of data. This implies that the entire sample data presented shows a non-Newtonian behaviour and can be represented by a Bingham plastic fluid. This behaviour can be expressed mathematically by equation (1) as:

$\tau=\tau_{y}+\eta_{p} \dot{\gamma}$

where $\tau=$ the shear stress, $\tau_{y}=$ the yield stress, $\eta_{p}=$ plastic viscosity and $\dot{\gamma}=$ the shear rate. The variation of shear stresses and apparent viscosities at various solid concentrations and the proportions of BA are presented in Figure 2. It is observed that shear stress and plastic viscosity were decreased with increasing the proportion of BA added to the slurry in the range of 10 to $30 \%$. At $40 \%$ addition of BA, the yield stress and shear viscosity were drastically increased at all solid mass concentrations (Figure 3 ). Hence, the minimum yield stress was

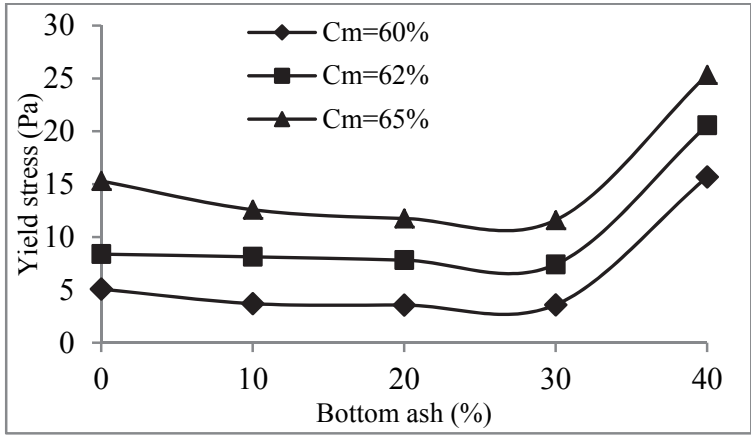

(a) Yield stress of FA slurry with the addition of BA observed at 30\% mixing ratio. As shown in Figure 3 the effects of BA addition was more manifested at $65 \%$ concentration. It is observed that the yield stress was reduced by $24 \%$ for a $30 \%$ addition of BA in the FA slurry at $65 \%$ solid mass concentration (Table 3). That is, the incremental rate of shear stress is highest at $65 \%$ solid concentration as the values of shear rate increases. It is also observed that for the same shear rate, addition of BA on the FA decreased the shear stress and apparent viscosity at the highest rate for $60 \%$ solid mass concentration.

\section{The effects of addition of FA on the BA slurry}

The addition of FA was done at proportions of $0,10,20,30$, 40 and $50 \%$ by mass for each solid concentration of $30 \%, 40 \%$ and $50 \%$ of BA slurry. Shear stress-shear rate curves, for BA without and with the addition of FA, are presented in Figure 4 (a-d). The corresponding shear stress curves for all BA slurries indicated that the shear stress increases with increasing shear rates. It is observed that for the same shear rate, the shear stress increases as the solid concentration increases. It is also indicated that the shear stress value is minimum for the BA slurry and increases with increasing the proportion of FA at different shear rates and solid mass concentrations. Similar trends were also observed by Biswas et al. (2000).

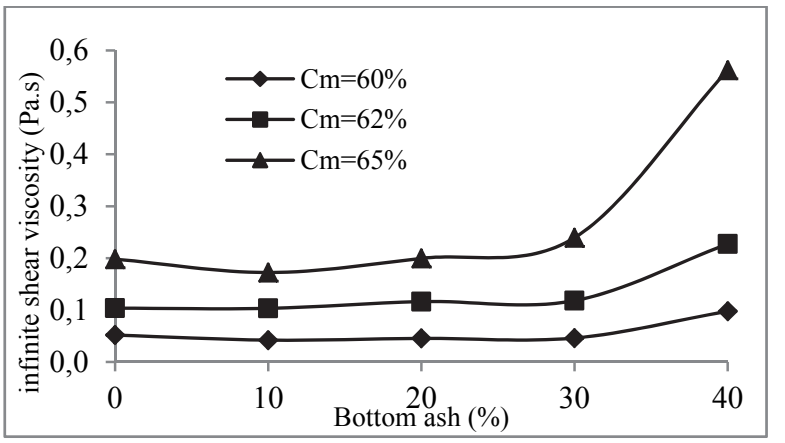

(b) Infinite shear viscosity of FA slurry with the addition of BA

Fig. 3(a-b). Yield stress \& infinite shear viscosity of FA slurry.

Table 3. Effects of adding BA on the rheological parameters of FA slurry.

\begin{tabular}{|c|c|c|c|c|c|c|}
\hline \multirow[b]{2}{*}{ BA $(\%)$} & \multicolumn{2}{|c|}{$\mathrm{C}_{\mathrm{m}}=60 \%$} & \multicolumn{2}{|c|}{$\mathrm{C}_{\mathrm{m}}=62 \%$} & \multicolumn{2}{|c|}{$\mathrm{C}_{\mathrm{m}}=65 \%$} \\
\hline & $\tau_{y}(P a)$ & $\eta_{\infty}($ Pa.s $)$ & $\tau_{y}(P a)$ & $\eta_{\infty}($ Pa.s $)$ & $\tau_{y}(P a)$ & $\eta_{\infty}($ Pa.s $)$ \\
\hline 0 & 5.1 & 0.0519 & 8.4 & 0.1036 & 15.3 & 0.1981 \\
\hline 10 & 3.7 & 0.0421 & 8.1 & 0.1034 & 12.6 & 0.1723 \\
\hline 20 & 3.6 & 0.0454 & 7.8 & 0.1163 & 11.8 & 0.1996 \\
\hline 30 & 3.6 & 0.0461 & 7.4 & 0.1182 & 11.6 & 0.2393 \\
\hline \multirow[t]{2}{*}{40} & 15.7 & 0.0977 & 20.6 & 0.2273 & 25.3 & 0.5621 \\
\hline & \multicolumn{2}{|c|}{$\mathrm{C}_{\mathrm{m}}=60 \%$} & \multicolumn{2}{|c|}{$\mathrm{C}_{\mathrm{m}}=62 \%$} & \multicolumn{2}{|c|}{$\mathrm{C}_{\mathrm{m}}=65 \%$} \\
\hline BA (\%) & Temp $\left({ }^{\circ} \mathrm{C}\right)$ & $\eta_{r}(-)$ & Temp $\left({ }^{\circ} \mathrm{C}\right)$ & $\eta_{r}(-)$ & Temp $\left({ }^{\circ} \mathrm{C}\right)$ & $\eta_{r}(-)$ \\
\hline 0 & 35 & 72.17 & 35 & 144.07 & 31 & 253.8 \\
\hline 10 & 35 & 58.55 & 35 & 143.79 & 31 & 220.75 \\
\hline 20 & 35 & 63.13 & 35 & 161.73 & 31 & 255.72 \\
\hline 30 & 35 & 64.11 & 35 & 164.37 & 31 & 306.59 \\
\hline 40 & 35 & 135.86 & 35 & 316.09 & 31 & 720.15 \\
\hline
\end{tabular}

$\eta_{r}=\eta_{\infty} / \eta_{l}$; and $\eta_{l}$ at $31^{\circ} \mathrm{C}$ and $35^{\circ} \mathrm{C}$ are $780.53 \mu \mathrm{Pa} . \mathrm{s}$ and $719.14 \mu \mathrm{Pa}$.s, respectively.

It is to be noted that $\eta_{\infty}=\eta_{p}$ for Bingham plastic slurries considered in the present study. 


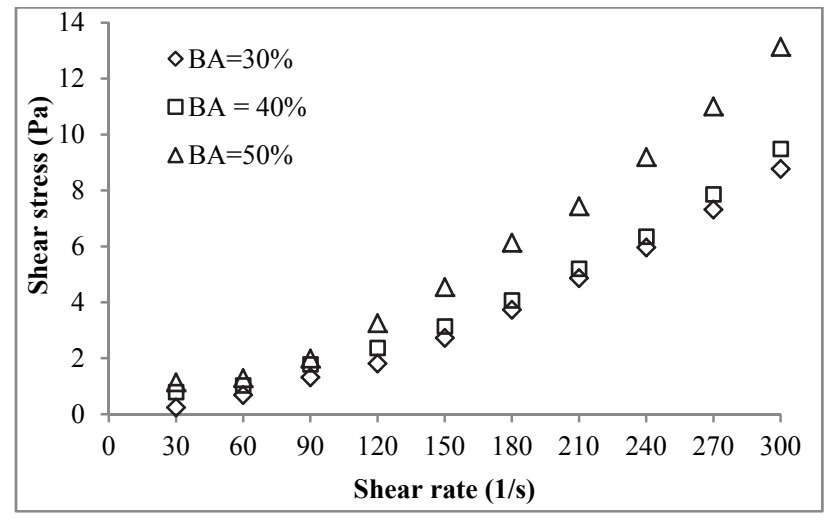

(a) Shear stress of BA slurry at various solid concentrations by weight

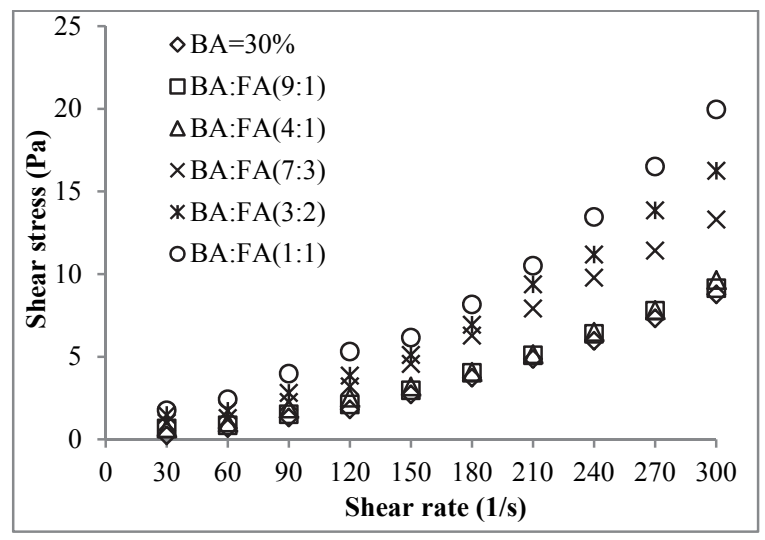

(b) $\mathrm{C}_{\mathrm{m}}=30 \%$

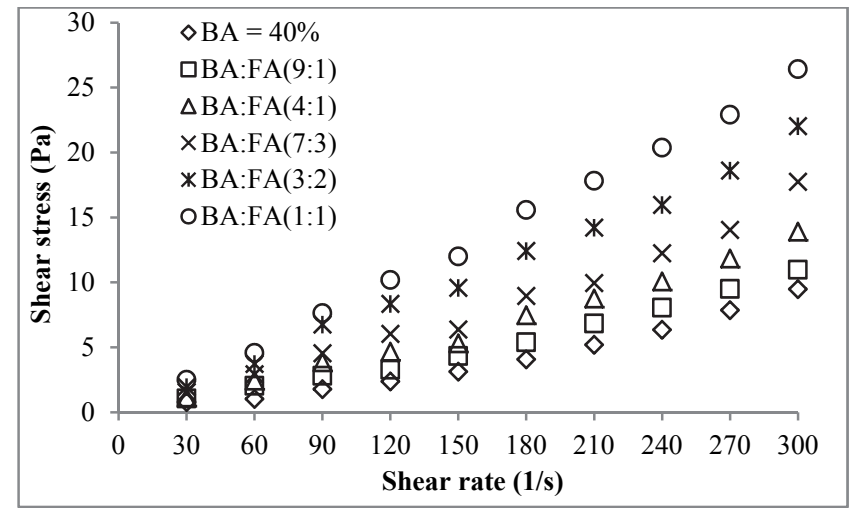

(c) $\mathrm{C}_{\mathrm{m}}=40 \%$

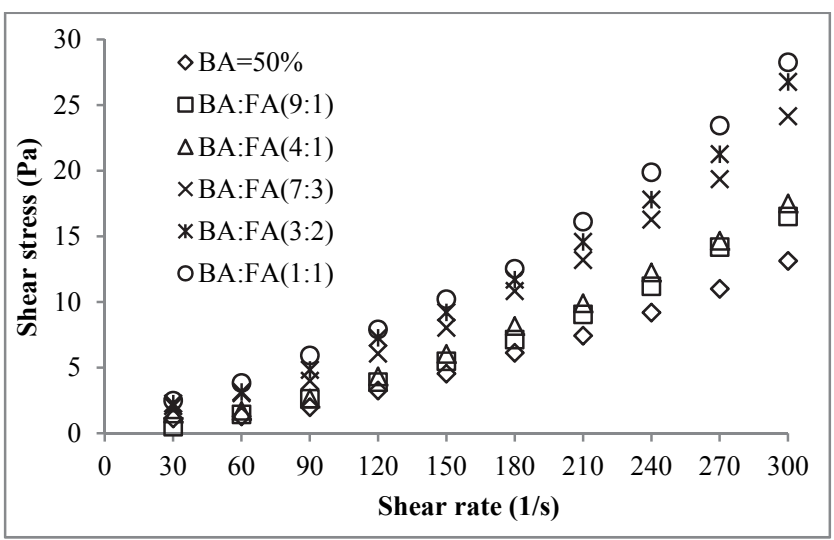

(d) $\mathrm{C}_{\mathrm{m}}=50 \%$

Fig. 4 (a-d). Rheogram of BA slurry without and with the addition of FA.

In an attempt to find the model that best describes the data, the linear model had higher $\mathrm{R}^{2}$ values, greater than 0.96 , than the power law. Hence, it can be seen that linear model best fitted to all the cases of BA slurries, suggesting that all the flow curves of BA slurries exhibited Newtonian behaviours. The straight line equation representing the experimental data curve is expressed by equation (2) as:

$\tau=\eta \dot{\gamma}$

where $\eta=$ apparent viscosity, $\tau=$ shear stress and $\dot{\gamma}=$ shear rate.

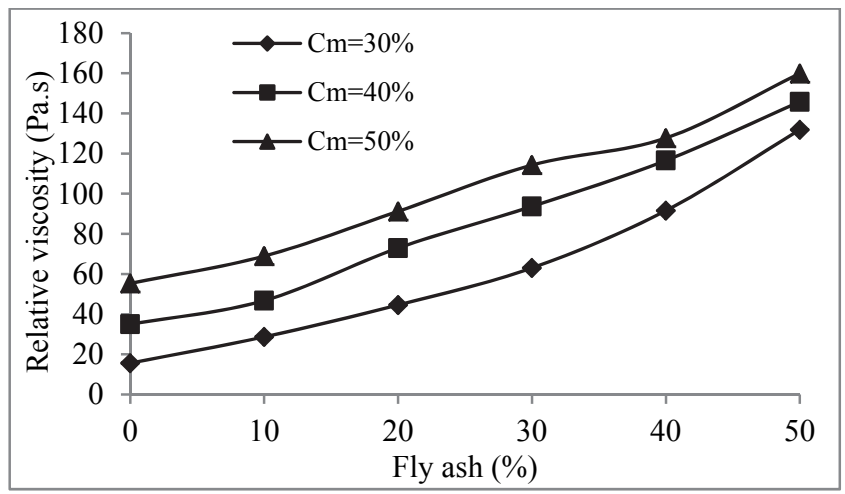

$\eta_{l}$ at $31^{\circ} \mathrm{C}$ is $780.53 \mu \mathrm{Pa} . \mathrm{s}$

Fig. 5. Relative viscosity of BA slurry without and with additon of FA.
The relative viscosity of BA slurry for all solid mass concentrations and proportions of FA are presented graphically in Figure 5. It is computed as the ratio of the viscosity of the slurry to the carrier fluid (water) at the same temperature. It is observed that increasing the proportion of FA in the BA slurry increases the relative viscosity. These increments might be due to the results of a greater effective solid surface area according to Chandel, et al. (2009b).

As shown in Figure 5, for the addition of 50\% proportions of FA, the relative viscosities have increased by eight, four and three times for $30 \%, 40 \%$ and $50 \%$ mass concentration of BA slurry respectively. Hence, the effect of addition of FA is more pronounced at the lower solid mass concentration of BA slurry.

\section{MATHEMATICAL FORMULATION FOR THE RELATIVE VISCOSITY}

The ability to control and predict the slurry flow processes is critically dependent on the rheological property of the slurry. This rheological property is commonly characterized by its shear stress and viscosity. The viscosity of the suspension $\left(\eta_{s}\right)$ is often normalized by the viscosity of the carrier liquid and is called relative viscosity as given in equation (3):

$\eta_{r}=\eta_{s} / \eta_{l}$

There are numerous equations that have been developed to predict the relative viscosity of mono-dispersed or polydispersed suspensions. One of the many equations developed 
for poly-dispersed suspensions considering the effects of maximum solid volume fraction $\left(\phi_{m}\right)$ is developed by Chong et al. (1971) and given in equation (4) as:

$\eta_{r}=\left[1+0.75 \frac{\left(\phi / \phi_{m}\right)}{\left(1-\phi / \phi_{m}\right)}\right]^{2}$

The volumetric fraction $(\phi)$ was computed from the solid mass concentration $\left(\mathrm{C}_{\mathrm{m}}\right)$ using equations (5) and (6) as follows:

$\phi=\frac{C_{v}}{100}$

$C_{v}=\frac{100 C_{m} / S}{\left(C_{m} / S\right)+\left(100-C_{m}\right)}$

where $C_{v}$, and $S$ are volumetric concentration and specific gravity of the solid respectively.

The effect of adding FA on the relative viscosity of BA slurry was analysed and an attempt has been made to develop a correlation to estimate the relative viscosity as a function of the proportion of FA added to the BA slurry and solid concentration by volume fraction based on the regression analysis. The present analysis is based on the above model developed by Chong et al. (1971).

Initially, a log-log graph was plotted for the relative viscosity of BA $\left(\eta_{r}\right)$ slurry with solid concentration fractions $\left(\phi / \phi_{m}\right)$ to obtain the functional relationship between them. Then, all the data of variation of relative viscosity due to addition of FA $(R)$ was plotted against the solid fractions. The functional relationship of the relative viscosity of BA slurry $\left(\eta_{r, \beta}\right)$ in terms of solid concentration in volume fraction $(\phi)$, maximum settled concentration in volume fraction $\left(\phi_{m}\right)$ and proportion of FA in mass fraction $(R)$ is given in equations (7) to (9) as:

$\eta_{r, \beta}=\left[37 \ln \left(\eta_{r}\right)+1\right] \exp (\alpha)$

$\eta_{r}=\left[1+0.75 \frac{\left(\phi / \phi_{m}\right)}{\left(1-\phi / \phi_{m}\right)}\right]^{2}$

$\alpha=\left(\frac{3.52}{1.24^{n}}\right) R$

$n$ is a coefficient depends on the solid mass concentration.

$n=\left\{\begin{array}{l}0 \text { for } C_{m}=30 \% \\ 1 \text { for } C_{m}=40 \% \\ 2 \text { for } C_{m}=50 \%\end{array}\right.$

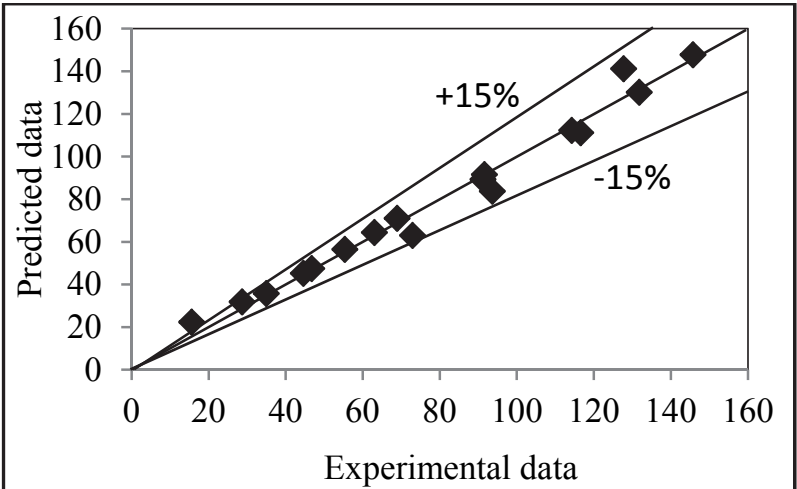

Fig. 6. Comparison of the experimental and predicted relative viscosity at $\pm 15 \%$.
From the statistical analysis the RMSE and $\mathrm{R}^{2}$ of the data are $11.98 \%$ and 0.988 respectively. It is also observed that there is a reasonable agreement of $95 \%$ of the relative viscosity data points lie within the deviation limits of $\pm 15 \%$ as shown in Figure 6.

\section{CONCLUSIONS}

The aim of this investigation is to evaluate the rheological properties of the FA slurry without and with the addition of BA and BA slurry without and with the addition of FA in proportion ranging from 10 to $50 \%$ by mass at solid concentration ranging from 30 to $65 \%$. The physical properties of the ashes such as $\mathrm{pH}, \mathrm{PSD}$, specific gravity and static settled concentration have also been studied. Computerized rotational Rheometer was used to determine the rheological behaviour of the slurries.

The study revealed that the FA slurry showed Bingham fluid behaviour at all studied solid concentrations and proportions of BA addition. The values of both shear stress and shear viscosity increased with increase in concentration and decreased with increasing proportions of BA added up to $30 \%$ by mass. Hence, the effective range of proportions of BA was found to be from $10 \%$ to $30 \%$ by mass.

Another important conclusion obtained from this study is that the BA slurries showed Newtonian behaviour at solid mass concentration of $30 \%, 40 \%$ and $50 \%$. This behaviour did not change with the addition of FA up to $50 \%$. The addition of FA to the BA slurry increases the relative viscosity for all concentrations and mixture proportions. These increments might be due to the results of a greater solids surface area as observed by other investigators.

Based on the results obtained it appears that the mechanical treatment may change significantly ash-water mixtures flow behaviour. This implies that the slurries have greater potential to be transported in pipelines at higher concentration so that a large amount of water and power can be saved.

\section{REFERENCES}

Biswas, A., Gandhi, B.K., Singh, S.N., Seshadri, V., 2000. Characteristics of coal ash and their role in hydraulic design of ash disposal pipelines. Indian Journal of Engineering and Material Science, 7, 1-7.

Chandel, S., Seshadri, V., Singh, S.N., 2009a. Effect of additive on pressure drop and rheological characteristics of fly ash slurry at high concentration. Particulate Science and Technology, 27, 3, 271-284.

Chandel, S., Singh, S.N., Seshadri, V., 2009b. Deposition characteristics of coal ash slurries at higher concentrations. Advanced Powder Technology, 20, 383-389.

Chandel, S., Seshadri, V., Singh, S.N., 2010. Transportation of high concentration coal ash slurries through pipelines. Inter. Archive of Applied Science and Technology, 1, 1, 1-9.

Chong, J.S., Christiansen, E.B., Baer, A.D., 1971. Rheology of concentrated suspensions. Journal of Applied Polymer Science, 15, 2007-2021.

Gahlot, V.K., Seshadri, V., Malhotra, R.C., 1988. A method for the experimental determination of the rheological parameters of multisized course particulate slurries. In: Inter. Symposium on Hydraulic Transportation of Coal and Other Minerals, IIT Delhi, March 4-6, pp. 283-295.

Kolar, V., Pollert, J., Sellin, R.H.J., Vlasak, P., 1988. Experiment with drag reducing polymer in an ash-slag hydro transport pipeline. Journal of Hydraulic Research, 26, 2, 143-158. 
Kunal, S., Kundan, L., 2012. Effect of Cetylpyridinium chloride, Triton X-100 and Sodium Dodecyl Sulphate on rheology of fly ash slurry. International Journal of Scientific and Research Publications, 2, 8, 1-5.

Mosa, S., Abdel, H.M.S., Taha, A., Anas, M.E., 2008. Effect of chemical additives on flow characteristics of coal slurries. J. of Physicochemical Problems of Mineral Processing, 42, 107-118.

Naik, H.K., Mishra, M.K., Rao Karanam, U.M., Deb, D., 2009a. Evaluation of the role of a cationic surfactant on the flow characteristics of fly ash slurry. Journal of Hazardous Materials, 169, 1134-1140.

Naik, H.K., Mishra, M.K., Rao Karanam, U.M., 2009b. The effect of drag reducing additives on the rheological properties of fly ash-water suspensions at varying temperature environment. Coal Combustion and Gasification Products, 1, $25-31$.

Naik, H.K., Mishra, M.K., Rao, K.U.M., 2011. Influence of chemical reagents on rheological properties of fly ash water slurry at varying temperature environment. Coal Combustion and Gasification Products, 3, 83-93.

Panda, D., Pradhan, B., 2014. Hydraulic transport of fly ash and fly ash- bottom ash mixtures at high concentrations. International Journal of Chemical Engineering and Applied Sciences, 4, 1, 1-4

Senapati, P.K., Mishra, B.K., 2012. Design considerations for hydraulic backfilling with coal combustion products (CCPs) at high solids concentrations. Powder Technology, 229, 119-125.

Senapati, P.K., Mishra, B.K., Parida, A., 2010. Modeling of viscosity for power plant ash slurry at higher concentrations: Effect of solids volume fraction, particle size and hydrodynamic interactions. Powder Technology, 197, 1-8.

Senapati, P.K., Mishra, B.K., Parida, A., 2013. Analysis of friction mechanism and homogeneity of suspended load for high concentration fly ash \& bottom ash mixture slurry using rheological and pipeline experimental data. Powder Technology, 250, 154-163.

Seshadri, V., Singh, S.N., Jain, K.K., Verma, A.K., 2005. Rheology of fly ash slurries at high concentrations and its application to the design of high concentration slurry disposal system (HCSD). In: Proceedings of the International Conference on Fly Ash Utilization, 1, 10.
Umesh, K., Mishra, R., Singh, S.N., Seshadri, V., 2003. Effect of particle gradation on flow characteristics of ash disposal pipelines. Powder Technology, 132, 39-51.

Verma, A.K., Singh, S.N., Seshadri, V., 2006. Pressure drop for the flow of high concentration solid liquid mixture $90^{\circ}$ horizontal conventional circular pipe bends. Indian Journal of Engineering and Material Science, 13, 477-483.

Vlasak, P., Chara, Z., 2004. Laminar and turbulent transition of fine-grained slurries. Particulate Science and Technology, 22, 2, 189-200.

Vlasak, P., Chara, Z., 2009. Conveying of solid particles in Newtonian and non-Newtonian carriers. Particulate Science and Technology, 27, 5, 428-443.

Vlasak, P., Chara, Z., 2011. Effect of particle size distribution and concentration on flow behaviour of dense slurries. Particulate Science and Technology, 29, 1, 53-65.

Vlasak, P., Chara, Z., Stern, P., 2010. Drag reduction of dense Fine-Grained slurries. Journal of Hydrology and Hydromechanics, 58, 4, 261-270.

\section{NOMENCLATURE}

$\begin{array}{ll}\text { BA } & \text { Bottom ash } \\ \text { FA } & \text { Fly ash } \\ \text { PSD } & \text { Particle size distribution } \\ S & \text { Solid specific gravity (-) } \\ \phi & \text { Solid volume fraction (-) } \\ \phi_{\mathrm{m}} & \text { Maximum static volume fraction (-) } \\ \mathrm{C}_{\mathrm{m}} & \text { Solid mass concentration (\%) } \\ \mathrm{C}_{\mathrm{v}} & \text { Solid volume concentration (\%) } \\ \tau & \text { Shear stress (Pa) } \\ \tau_{y} & \text { Yield stress (Pa) } \\ \eta_{p} & \text { Plastic viscosity (Pa.s) } \\ \eta_{\infty} & \text { Infinite shear viscosity (Pa.s) } \\ \eta_{1} & \text { Fluid carrier(water) viscosity (Pa.s) } \\ \eta_{\mathrm{r}} & \text { Relative viscosity (-) } \\ \eta_{r, \beta} & \text { Relative viscosity of the BA slurry (-) }\end{array}$

Received 10 November 2014 Accepted 1 April 2015 